\section{(2) OPEN ACCESS}

\title{
Household disposable income and long-term survival after pulmonary resections for lung cancer
}

\author{
Erik Sachs, ${ }^{1,2}$ Veronica Jackson (D) ,' Ulrik Sartipy (D) 1,2
}

\begin{abstract}
- Additional material is published online only. To view please visit the journal online (http://dx.doi.org/10.1136/ thoraxjnl-2019-214321).
\end{abstract}

${ }^{1}$ Department of Molecular Medicine and Surgery, Karolinska Institutet, Stockholm, Sweden

${ }^{2}$ Department of Cardiothoracic Surgery, Karolinska University Hospital, Stockholm, Sweden

\section{Correspondence to}

Dr Veronica Jackson, Department of Molecular Medicine and Surgery, Karolinska Institutet, Karolinska University Hospital, Stockholm SE-17176, Sweden; Veronica.Jackson@ki.se

VJ and US contributed equally.

Received 12 November 2019 Revised 27 April 2020 Accepted 11 May 2020 Published Online First 20 June 2020
Check for updates

(c) Author(s) (or their employer(s)) 2020. Re-use permitted under CC BY-NC. No commercial re-use. See rights and permissions. Published by BMJ.

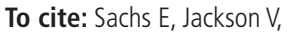
Sartipy U. Thorax

2020;75:764-770.

\section{ABSTRACT \\ Introduction Socioeconomic disparities have been} linked to survival differences in patients with lung cancer. Swedish healthcare is tax-funded and provides equal access to care, therefore, survival following lung cancer surgery should be unrelated to household income. The aim of this study was to investigate the association between household disposable income and survival following surgery for lung cancer in Sweden.

Methods We conducted a nationwide populationbased cohort study including all patients who underwent pulmonary resections for lung cancer in Sweden 20082017. Individual-level record linkages between national quality and health-data registers were performed to acquire information regarding socioeconomic status and medical history. Cox regression by quintiles of household disposable income was used to estimate the adjusted risk for all-cause mortality.

Results We included 5500 patients and the ageadjusted and sex-adjusted incidence rate of death per 100 person-years was 15 and 9.4 in the lowest and highest income quintile, respectively (mean follow-up time 3.2 years). Deprived patients were older, had more comorbidities and were less likely to have preoperative positron emission tomography or minimally invasive surgery, compared with patients with higher income. The adjusted HR for death was 0.77 (95\% Cl: 0.62 to 0.96) for the highest income quintile compared with the lowest.

Conclusions We found an association between household disposable income and survival in patients who underwent surgery for lung cancer in Sweden, despite tax-funded universal health coverage. The association remained after adjustment for differences in baseline characteristics.

\section{INTRODUCTION}

There are known differences in life expectancy and causes of death related to household income. In addition, the gap in life expectancy between the richest and the poorest is increasing and can largely be attributed to differences in deaths from cardiovascular disease and cancers. ${ }^{1-5}$

There are several reports of socioeconomic disparities influencing lung cancer survival by means of unequal access to surgical care.$^{6-8}$ Sweden has a tax-funded universal healthcare system that aims to provide equal medical care to all residents regardless of income or employment status. Nonetheless, differences in socioeconomic status have been linked to both lung cancer survival and the management of lung cancer in Sweden. ${ }^{10}$ The

\section{Key messages}

What is the key question?

- Is household disposable income related to survival differences in patients with lung cancer.

What is the bottom line?

- Swedish healthcare is tax-funded and provides equal access to care, therefore, survival following lung cancer surgery should be unrelated to household disposable income.

Why read on?

- We found an association between household disposable income and survival in patients who underwent surgery for lung cancer in Sweden, despite tax-funded universal health coverage.

likelihood of receiving surgical treatment for lung cancer in Sweden has previously been linked to educational level but the association could not be corroborated in a more recent cohort. ${ }^{9}{ }^{10}$ In a contemporary Swedish nationwide cohort of cardiac surgery patients, a strong inverse correlation between household income and mortality was found. ${ }^{11}$ Whether such an association also exists for patients undergoing lung cancer surgery in Sweden remains unknown. The aim of this study was to investigate the association between household disposable income and survival following pulmonary resections for lung cancer in Sweden.

\section{METHODS}

The reporting in this nationwide population-based observational cohort study follows the Strengthening the Reporting of Observational Studies in Epidemiology and the REporting of studies Conducted using Observational Routinely collected health Data guidelines for observational studies using routinely collected data. ${ }^{12}$

\section{Study population}

The study population was identified using the Swedish national quality register for general thoracic surgery (ThoR). ${ }^{14}$ The ThoR Register contains detailed information on patient characteristics and surgical procedures for patients who have undergone general thoracic surgery in Sweden. The ThoR Register was started in 2008 and in 2013 a complete coverage of all eight thoracic surgery departments in Sweden was achieved. From 2009 to 2011, approximately 50\% of all patients who underwent thoracic surgery in Sweden were 
included, and during 2011 and 2012, seven out of eight hospitals reported to the register.

\section{Data collection}

Record linkages between the ThoR Register and other nationwide healthcare registers were performed by the Swedish National Board of Health and Welfare using the unique personal identity number that is assigned to all Swedish residents, and the study database was subsequently anonymised. ${ }^{15}$ Information on previous relevant medical history was retrieved from the National Patient Register. ${ }^{16}$ Household income and composition and individual educational level was obtained from the Longitudinal Integration Database for Insurance and Labour Market Studies (LISA), which is managed by the government agency Statistics Sweden. ${ }^{17}$ In brief, the LISA database is updated yearly and contains information on demographics, education, employment and income at individual and family-level. The sum of all taxable income minus final tax and other negative transfers is defined as the household disposable income in the LISA database. For this study, the household disposable income was calculated as the mean of all yearly household disposable income figures for each patient through the calendar year of surgery. Household composition was categorised into three categories: two adults without children, one adult without children and one or two adults with one or more child(ren). Educational level was categorised as $<10$ years, $10-12$ years and $>12$ years.

\section{Outcomes}

The outcome measure was time to death from any cause. Information regarding vital status and date of death was obtained from the Swedish Population Register. ${ }^{18}$

\section{Definitions}

Smoking was divided into four categories; never (a person who had never actively smoked), former (smoking cessation more than 1 month prior to surgery), current (active smoker or smoking cessation within 1 month of surgery) and unknown. Performance status was defined according to the Eastern Cooperative Oncology Group/WHO. ${ }^{19}$ Performance status grades 2 and 3 were collapsed into one category. Information regarding previous or concurrent medical conditions was obtained from the ThoR Register or the National Patient Register using International Classification of Diseases codes. ${ }^{16}$ The extent of surgery was categorised into two categories: sublobar resections versus lobectomy, bilobectomy, or pneumectomy.

\section{Statistical analysis}

We categorised household disposable income according to quintiles from the lowest (Q1) to the highest (Q5) income. Each quintile represents one-fifth $(\mathrm{n}=1100)$ of the study population. Baseline characteristics were described with frequencies and percentages for categorical variables and means and SD for continuous variables. Person-time in days was counted from the date of surgery until the date of death or end of follow-up (10 January 2019). The Kaplan-Meier method was used to calculate cumulative survival. We calculated age-adjusted and sexadjusted incidence rates and 95\% CIs using a Poisson model. We used Cox proportional hazards regression with and without multivariable adjustment to estimate $\mathrm{HRs}$ and $95 \% \mathrm{CI}$ for the association between quintiles of household disposable income and survival using the lowest income quintile as the reference category. In addition, the household disposable income was modelled as a continuous variable using restricted cubic splines with three knots in a Cox regression model. The reference level was set at 60000 Swedish Krona for the estimation of HRs. The Cox model was adjusted for all variables listed in table 1 and stratified by histopathology, pathological stage, household composition and hospital.

Missing data (positron emission tomography (PET) (6.8\%), body mass index (5.9\%), $\mathrm{FEV}_{1}(5.9 \%)$, lymph node sampling $(2.6 \%)$, chemotherapy $(2.3 \%)$ and radiotherapy $(2.3 \%))$ were handled by multiple imputation by chained equations. ${ }^{20}$ The imputation models included all variables in table 1 , year of surgery, hospital, and also the event indicator and the NelsonAalen estimator of the cumulative baseline hazard. ${ }^{21}$ Ten data sets were imputed and estimates from these data sets were combined according to Rubin's rules. The statistical analyses were performed with Stata V.16.0 (StataCorp LP, College Station, Texas, USA) and R V.3.6.1 (R Foundation for Statistical Computing, Vienna, Austria).

\section{RESULTS}

Data on all patients who had undergone pulmonary resections for lung cancer, and who were registered in ThoR, from 2008 until 2017, were extracted. The study flow chart and exclusion criteria are shown in online supplementary figure 1. Baseline characteristics according to household disposable income quintiles are presented in table 1 .

The distribution of household disposable income in the study population is shown in figure 1 . The study population consisted of 5500 patients and the mean age was 68 years, $55 \%$ were women and $30 \%$ were current smokers. Patients with lower household disposable income were more likely to be female, of older age and had more comorbidities (COPD, heart failure, diabetes mellitus, prior stroke or transient ischaemic attack and peripheral vascular disease) compared with patients with higher disposable income. Furthermore, patients with lower household disposable income were more likely to be current smokers and to have an alcohol dependency but less likely to be never, or former, smokers than patients with higher disposable income. Performance status of higher grade (ie, lesser functional level) and a lower $\mathrm{FEV}_{1}$ were more often seen in patients in the lower household disposable income quintiles. In addition, patients with lower household disposable income were less likely to have had undergone preoperative PET, less likely to have had undergone minimally invasive surgery (video-assisted thoracic surgery (VATS)) and more likely to be diagnosed with lung cancer of unknown histopathology. Squamous cell lung cancer was more common in patients with lower household disposable income whereas patients with higher disposable income were more often diagnosed with adenocarcinoma. There were small differences in pathological tumour stage related to household disposable income, however, the disparities were unlikely to be of clinical relevance. A higher proportion of patients in the lower income quintiles had shorter education compared with patients in higher income quintiles.

\section{FOLLOW-UP AND MORTALITY}

During a mean follow-up time of 3.2 years, 1736 patients died. Event rates and crude and adjusted risks for all-cause mortality are shown in table 2 . Sensitivity analyses are reported in online supplementary table 1.

For patients with the lowest household disposable income the number of deaths per person-years was 407/3374 as compared with 282/3423 for patients with the highest household disposable income. The unadjusted Kaplan-Meier estimated survival 
Table 1 Baseline characteristics in 5500 patients who underwent pulmonary resections for lung cancer in Sweden during 2008-2017 according to quintiles of household disposable income

\begin{tabular}{|c|c|c|c|c|c|c|c|}
\hline & & Household di & osable incom & by quintile & & & \\
\hline & All patients & Q1 (low) & Q2 & Q3 & Q4 & Q5 (high) & $P$ value \\
\hline Number of patients & 5500 & 1100 & 1100 & 1100 & 1100 & 1100 & \\
\hline Age, years, mean (SD) & $68.0(8.1)$ & $69.3(8.4)$ & $68.7(8.3)$ & $68.7(8.2)$ & $67.7(7.5)$ & $65.5(7.8)$ & $<0.001$ \\
\hline Female sex & $3030(55.1)$ & $680(61.8)$ & $616(56.0)$ & $584(53.1)$ & $576(52.4)$ & $574(52.2)$ & $<0.001$ \\
\hline Body mass index, $\mathrm{kg} / \mathrm{m}^{2}$, mean (SD) & $25.9(4.8)$ & $25.9(5.0)$ & $25.6(5.0)$ & $26.0(4.7)$ & $26.0(4.5)$ & $26.2(4.7)$ & 0.107 \\
\hline Household composition & & & & & & & $<0.001$ \\
\hline Two adults, no children & $2425(44.1)$ & $56(5.1)$ & $295(26.8)$ & $642(58.4)$ & $768(69.8)$ & $664(60.4)$ & \\
\hline One adult, no children & $2260(41.1)$ & $1016(92.4)$ & $711(64.6)$ & $334(30.4)$ & $126(11.5)$ & $73(6.6)$ & \\
\hline $1-2$ adults and $\geq 1$ child(ren) & $815(14.8)$ & $28(2.5)$ & $94(8.5)$ & $124(11.3)$ & $206(18.7)$ & $363(33.0)$ & \\
\hline Education & & & & & & & $<0.001$ \\
\hline$<10$ years & $1981(36.0)$ & $500(45.5)$ & $461(41.9)$ & $392(35.6)$ & $383(34.8)$ & $245(22.3)$ & \\
\hline $10-12$ years & $2452(44.6)$ & $499(45.4)$ & $484(44.0)$ & $512(46.5)$ & $504(45.8)$ & $453(41.2)$ & \\
\hline$>12$ years & $1067(19.4)$ & $101(9.2)$ & $155(14.1)$ & $196(17.8)$ & $213(19.4)$ & $402(36.5)$ & \\
\hline Household disposable income, kSEK, mean (SD) & $311(171)$ & $128(233)$ & $201(210)$ & $273(228)$ & $372(340)$ & $580(142)$ & $<0.001$ \\
\hline Smoking status & & & & & & & $<0.001$ \\
\hline Never smoker & $851(15.5)$ & $141(12.8)$ & $151(13.7)$ & $178(16.2)$ & $175(15.9)$ & $206(18.7)$ & \\
\hline Former smoker & $2907(52.9)$ & $493(44.8)$ & $570(51.8)$ & $589(53.5)$ & $629(57.2)$ & $626(56.9)$ & \\
\hline Current smoker & $1644(29.9)$ & $442(40.2)$ & $355(32.3)$ & $315(28.6)$ & $278(25.3)$ & $254(23.1)$ & \\
\hline Unknown & $98(1.8)$ & $24(2.2)$ & $24(2.2)$ & $18(1.6)$ & $18(1.6)$ & $14(1.3)$ & \\
\hline Alcohol dependency & $330(6.0)$ & $120(10.9)$ & $69(6.3)$ & $56(5.1)$ & $46(4.2)$ & $39(3.5)$ & $<0.001$ \\
\hline Preoperative $\mathrm{FEV}_{1}, \mathrm{~L}$, mean (SD) & $2.24(0.68)$ & $2.07(0.64)$ & $2.18(0.68)$ & $2.22(0.64)$ & $2.26(0.67)$ & $2.46(0.72)$ & $<0.001$ \\
\hline Performance status & & & & & & & $<0.001$ \\
\hline 0 & $3411(62.0)$ & $622(56.5)$ & $666(60.5)$ & $666(60.5)$ & $703(63.9)$ & $754(68.5)$ & \\
\hline 1 & $1984(36.1)$ & $451(41.0)$ & $411(37.4)$ & $410(37.3)$ & $377(34.3)$ & $335(30.5)$ & \\
\hline $2-3$ & $105(1.9)$ & $27(2.5)$ & $23(2.1)$ & $24(2.2)$ & $20(1.8)$ & $11(1.0)$ & \\
\hline Hypertension & $2043(37.1)$ & $429(39.0)$ & $425(38.6)$ & $408(37.1)$ & $403(36.6)$ & $378(34.4)$ & 0.169 \\
\hline Ischaemic heart disease & $972(17.7)$ & $217(19.7)$ & $192(17.5)$ & $198(18.0)$ & $198(18.0)$ & $167(15.2)$ & 0.089 \\
\hline Atrial fibrillation & 475 (8.6) & $98(8.9)$ & $96(8.7)$ & $93(8.5)$ & $102(9.3)$ & $86(7.8)$ & 0.798 \\
\hline Hyperlipidaemia & $693(12.6)$ & $148(13.5)$ & $139(12.6)$ & $146(13.3)$ & $129(11.7)$ & $131(11.9)$ & 0.659 \\
\hline Heart failure & $295(5.4)$ & $82(7.5)$ & $52(4.7)$ & $62(5.6)$ & $55(5.0)$ & $44(4.0)$ & 0.005 \\
\hline COPD & $991(18.0)$ & $251(22.8)$ & $221(20.1)$ & $210(19.1)$ & $171(15.5)$ & $138(12.5)$ & $<0.001$ \\
\hline Diabetes mellitus & $763(13.9)$ & $170(15.5)$ & $157(14.3)$ & $154(14.0)$ & $172(15.6)$ & $110(10.0)$ & 0.001 \\
\hline Prior stroke/TIA & $507(9.2)$ & $121(11.0)$ & $116(10.5)$ & $99(9.0)$ & $83(7.5)$ & $88(8.0)$ & 0.016 \\
\hline Peripheral vascular disease & $454(8.3)$ & $108(9.8)$ & $108(9.8)$ & $94(8.5)$ & $80(7.3)$ & $64(5.8)$ & 0.002 \\
\hline Chronic kidney disease & $114(2.1)$ & $20(1.8)$ & $29(2.6)$ & $24(2.2)$ & $21(1.9)$ & $20(1.8)$ & 0.621 \\
\hline Preoperative radiotherapy & $166(3.1)$ & $38(3.5)$ & $26(2.4)$ & $32(3.0)$ & $34(3.2)$ & $36(3.3)$ & 0.630 \\
\hline Preoperative chemotherapy & $224(4.2)$ & $46(4.3)$ & $35(3.3)$ & $42(3.9)$ & $43(4.0)$ & $58(5.4)$ & 0.174 \\
\hline Preoperative PET & $4615(90.0)$ & $898(88.2)$ & $915(90.3)$ & $909(89.0)$ & $923(90.2)$ & $970(92.1)$ & 0.039 \\
\hline Lobectomy or more & $4465(81.2)$ & $884(80.4)$ & $900(81.8)$ & $876(79.6)$ & $897(81.5)$ & $908(82.5)$ & 0.416 \\
\hline VATS & $1166(21.2)$ & $207(18.8)$ & $213(19.4)$ & $216(19.6)$ & $231(21.0)$ & $299(27.2)$ & $<0.001$ \\
\hline Expanded surgery* & $230(4.2)$ & $57(5.2)$ & $44(4.0)$ & $52(4.7)$ & $37(3.4)$ & $40(3.6)$ & 0.177 \\
\hline Lymph node sampling & $4610(86.1)$ & $920(86.0)$ & $922(86.5)$ & $901(84.4)$ & $916(85.2)$ & $951(88.4)$ & 0.083 \\
\hline Incomplete resection & $258(4.7)$ & $48(4.4)$ & $59(5.4)$ & $52(4.7)$ & $53(4.8)$ & $46(4.2)$ & 0.725 \\
\hline Postoperative histopathology & & & & & & & $<0.001$ \\
\hline Squamous cell lung cancer & $1036(18.8)$ & $242(22.0)$ & $240(21.8)$ & $190(17.3)$ & $209(19.0)$ & $155(14.1)$ & \\
\hline Adenocarcinoma & $3266(59.4)$ & $592(53.8)$ & $632(57.5)$ & $656(59.6)$ & $656(59.6)$ & $730(66.4)$ & \\
\hline Other & $638(11.6)$ & $127(11.5)$ & $127(11.5)$ & $134(12.2)$ & $132(12.0)$ & $118(10.7)$ & \\
\hline
\end{tabular}


Table 1 Continued

\begin{tabular}{|c|c|c|c|c|c|c|c|}
\hline & \multirow[b]{2}{*}{ All patients } & \multicolumn{5}{|c|}{ Household disposable income by quintile } & \multirow[b]{2}{*}{$P$ value } \\
\hline & & Q1 (low) & Q2 & Q3 & Q4 & Q5 (high) & \\
\hline Unknown & $560(10.2)$ & 139 (12.6) & $101(9.2)$ & $120(10.9)$ & $103(9.4)$ & $97(8.8)$ & \\
\hline Staget & & & & & & & 0.055 \\
\hline $\mathrm{IA}$ & $2148(39.1)$ & $398(36.2)$ & $408(37.1)$ & $443(40.3)$ & $431(39.2)$ & $468(42.5)$ & \\
\hline IB & $1276(23.2)$ & $271(24.6)$ & $282(25.6)$ & $252(22.9)$ & $251(22.8)$ & $220(20.0)$ & \\
\hline$\| A$ & $701(12.7)$ & 139 (12.6) & $148(13.5)$ & $143(13.0)$ & $139(12.6)$ & $132(12.0)$ & \\
\hline IIB & $608(11.1)$ & $129(11.7)$ & $133(12.1)$ & $115(10.5)$ & $118(10.7)$ & $113(10.3)$ & \\
\hline IIIA & 767 (13.9) & $163(14.8)$ & $129(11.7)$ & $147(13.4)$ & $161(14.6)$ & $167(15.2)$ & \\
\hline
\end{tabular}

Data are $\mathrm{n}(\%)$ unless otherwise noted.

${ }^{*}$ If any structure other than the lung or lymph nodes was included in the resection (eg, pericardium, diaphragm, thoracic wall).

tPathological stage.

KSEK, 1000 Swedish Krona; PET, positron emission tomography; Q, quintile; TIA, transient ischaemic attack; VATS, video-assisted thoracic surgery.

is shown in figure 2. The age-adjusted and sex-adjusted incidence rate of death per 100 person-years was 15 in the lowest income quintile compared with 9.4 in the highest income quintile. The crude, age-adjusted and sex-adjusted, and multivariable adjusted HR and $95 \%$ CI for all-cause mortality for patients with the highest disposable income $(\mathrm{Q} 5)$ was 0.68 (0.59 to 0.79$)$, 0.69 (0.59 to 0.80 ) and 0.77 (0.62 to 0.96$)$, respectively, as compared with patients with the lowest household disposable income (Q1). The association between household disposable income as a continuous variable and all-cause mortality is shown in online supplementary figure 2 . The figure shows that the adjusted risk of death decreases linearly by increasing household disposable income with an inflection point located slightly above the median household disposable income. The decrease in the adjusted risk of death is less pronounced at household disposable income levels above the 75 th percentile.

\section{DISCUSSION}

In this nationwide population-based study of patients undergoing pulmonary resections for lung cancer in Sweden, we found an inverse association between household disposable income and all-cause mortality. Patients in the lower household disposable income groups had a higher prevalence of cardiovascular risk factors as well as other prognostic factors known to be associated with worse cancer survival. However, the association between household disposable income and mortality remained after adjustment for differences in baseline characteristics.

There are several previous reports of an influence of socioeconomic status on lung cancer survival. ${ }^{622} 23$ It has been suggested that this association might be mediated by differences in access or quality of healthcare, and in particular the likelihood of receiving surgical treatment for lung cancer. ${ }^{67}$ There are studies

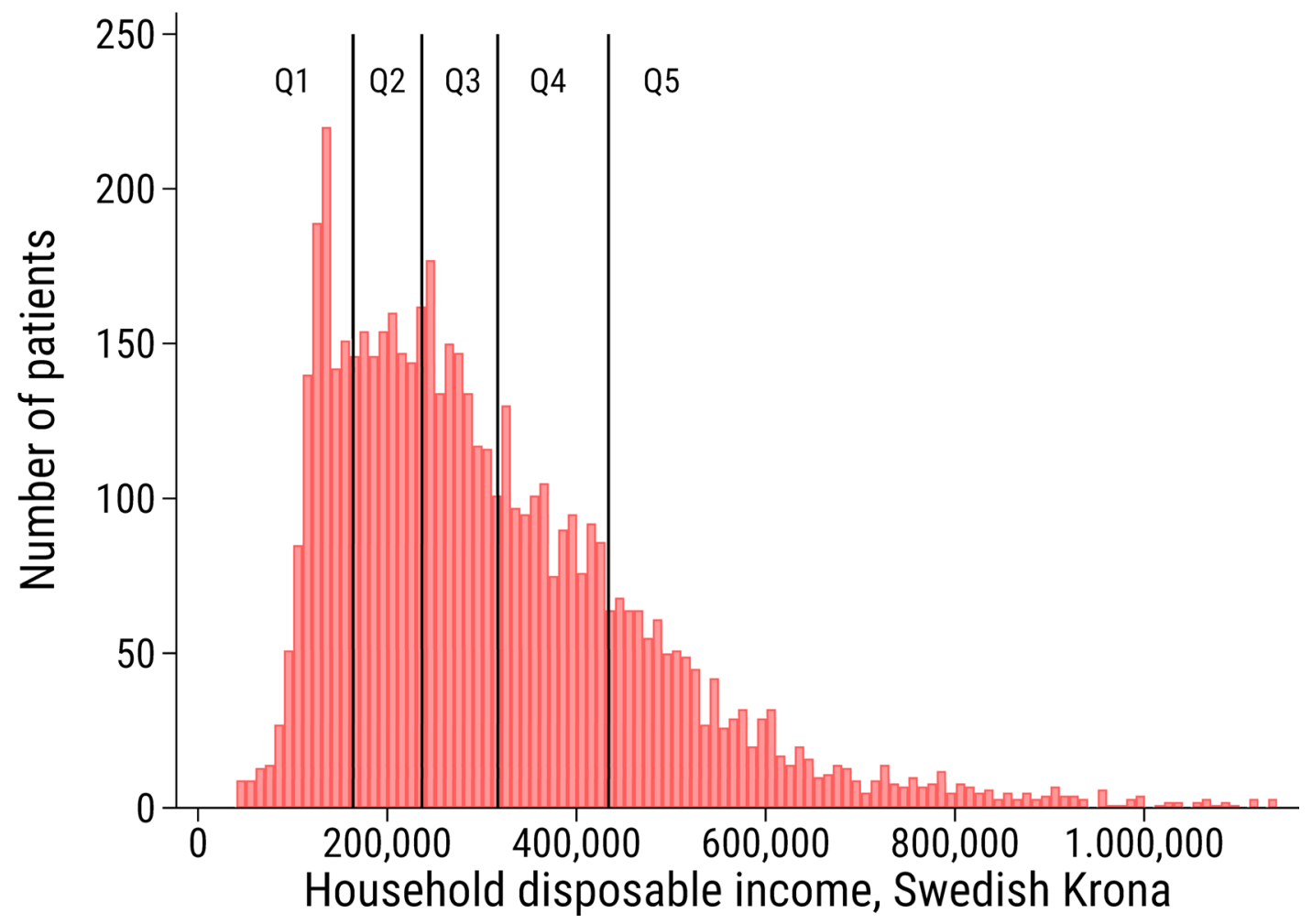

Figure 1 The distribution of household disposable income by quintiles (Q) in 5500 patients who underwent pulmonary resections for lung cancer in Sweden from 2008 to 2017. 
Table 2 Event rates and relative risks for all-cause mortality following pulmonary resections for lung cancer in Sweden during 2008-2017 according to quintiles of household disposable income

\begin{tabular}{|c|c|c|c|c|c|}
\hline $\begin{array}{l}\text { Household disposable } \\
\text { income, quintiles }\end{array}$ & $\begin{array}{l}\text { Number of deaths per } \\
\text { person-years }\end{array}$ & $\begin{array}{l}\text { Incidence rate* per } 100 \\
\text { person-years } \\
(95 \% \mathrm{Cl})\end{array}$ & Crude HR $(95 \% \mathrm{Cl})$ & $\begin{array}{l}\text { Age-adjusted and sex- } \\
\text { adjusted } \mathrm{HR}(95 \% \mathrm{Cl})\end{array}$ & $\begin{array}{l}\text { Multivariable adjusted } † \\
\text { HR }(95 \% \mathrm{CI})\end{array}$ \\
\hline Q1 (lowest)‡ & $407 / 3374$ & 15 (13 to 16$)$ & 1 & 1 & 1 \\
\hline Q2 & $375 / 3516$ & 12 (11 to 14$)$ & 0.89 (0.77 to 1.02$)$ & 0.86 (0.75 to 0.99$)$ & $0.85(0.72$ to 1.00$)$ \\
\hline Q3 & $335 / 3565$ & 11 (10 to 12$)$ & $0.78(0.68$ to 0.90$)$ & 0.75 (0.65 to 0.87$)$ & $0.73(0.61$ to 0.88$)$ \\
\hline Q4 & $337 / 3531$ & 11 (10 to 12$)$ & 0.79 (0.69 to 0.92$)$ & 0.78 (0.67 to 0.90$)$ & $0.76(0.62$ to 0.92$)$ \\
\hline Q5 (highest) & $282 / 3423$ & $9.4(8.2$ to 10$)$ & 0.68 (0.59 to 0.79$)$ & $0.69(0.59$ to 0.80$)$ & 0.77 (0.62 to 0.96$)$ \\
\hline
\end{tabular}

${ }^{*}$ Age-adjusted and sex-adjusted incidence rate.

†Multivariable adjustment was made for all variables reported in table 1.

‡Reference category.

Q, quintile.

that corroborate the association between socioeconomic factors and the likelihood of receiving surgery. ${ }^{8}$ However, others have shown no evident difference in survival among the patients that do undergo surgical treatment. ${ }^{24}$

Studies addressing disparities in the receipt of lung cancer surgery have been performed in countries without universal health coverage and a link between economic deprivation and survival has been found. ${ }^{78}$ However, an association between socioeconomic disparities and survival has also been noted in countries with universal health coverage. ${ }^{6}{ }^{25}$ Maruthappu et al evaluated possible effects of changes in unemployment and healthcare public-sector expenditure on cancer mortality in 75 different countries. A positive correlation between unemployment and cancer mortality was found and universal health coverage seemed to mitigate this effect. ${ }^{22}$ Differences in access to healthcare was put forward as a plausible explanation for the findings. $^{22}$
Sweden has a tax-funded universal healthcare system which in theory should entail equal access and quality of healthcare for all residents regardless of income or employment status. Yet, in the present cohort, patients with lower household disposable income were found to have an increased risk of death after lung cancer surgery as compared with the more affluent patients. The increased risk of death could not be attributed to differences in educational level, risk factor profile, or comorbidities. Thus, as in the Swedish nationwide study by Dalén et al, who found an inverse correlation between household disposable income and survival after cardiac surgery, our results suggest that incomerelated disparities in survival after pulmonary resections for lung cancer cannot fully be explained by differences in baseline risk factors or access to healthcare in a Swedish context. ${ }^{11}$

In a study by Mackenbach et al, a comparison of health inequalities between 22 European countries was performed. ${ }^{26}$ Despite having universal healthcare systems and a longstanding

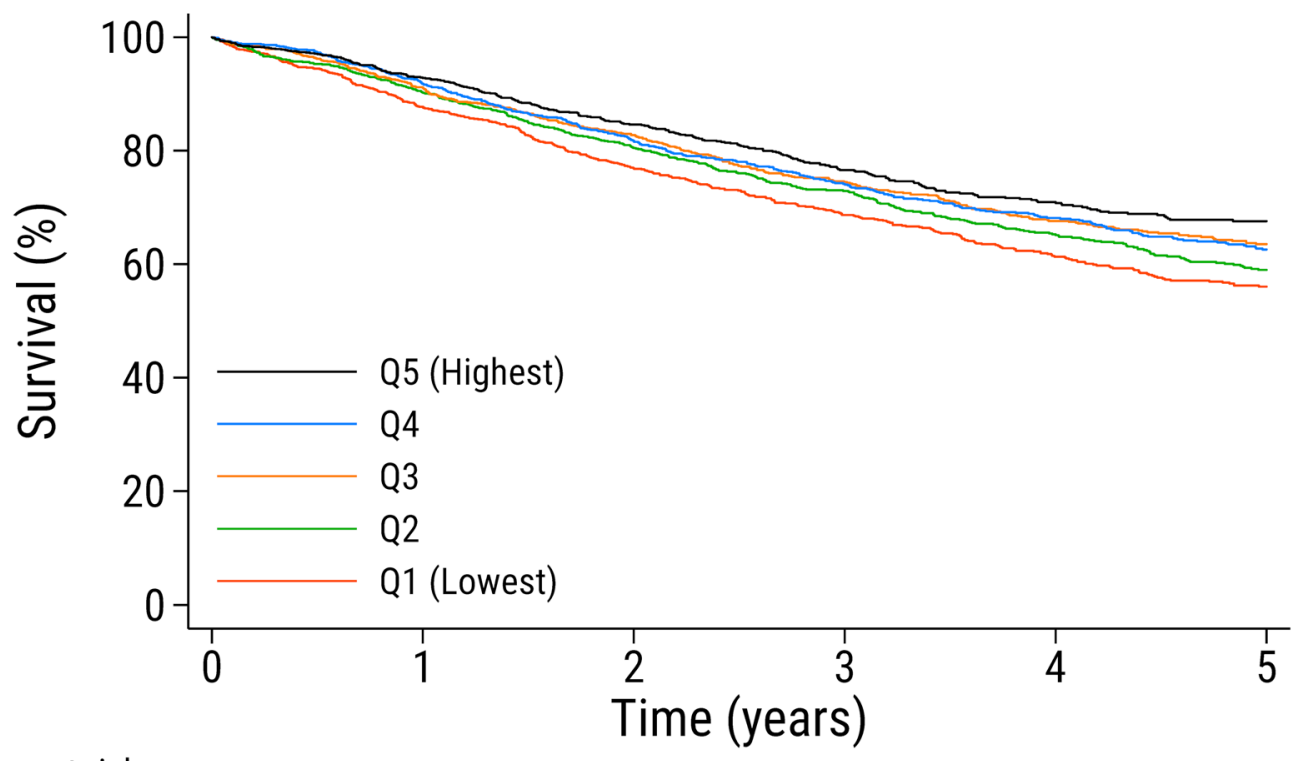

$\begin{array}{lcccccc}\text { Number at risk } & & & & & \\ \text { Q5 (Highest) } & 1100 & 1021 & 776 & 562 & 391 & 271 \\ \text { Q4 } & 1100 & 1010 & 770 & 582 & 455 & 342 \\ \text { Q3 } & 1100 & 1002 & 792 & 596 & 458 & 342 \\ \text { Q2 } & 1100 & 993 & 784 & 596 & 441 & 321 \\ \text { Q1 (Lowest) } & 1100 & 965 & 748 & 561 & 401 & 302\end{array}$

Figure 2 Unadjusted Kaplan-Meier estimated survival according to household disposable income by quintiles (Q) in 5500 patients who underwent pulmonary resections for lung cancer in Sweden from 2008 to 2017. 
tradition of equality and welfare policies the Nordic countries, Denmark, Sweden, Norway and Finland, were not found to have systematically smaller health inequalities than other European countries. The authors propose that social security and public services alone are not sufficient to eliminate inequalities in health and point out that lifestyle factors appear to uphold disparities in mortality in high-income countries. In a study investigating socioeconomic inequalities in lung cancer mortality in Europe, the largest contribution of lung cancer mortality to the total mortality was seen among women in Denmark, Norway and Sweden. ${ }^{23}$ The conclusion that socioeconomic inequalities in lung cancer mortality coincides with the geographical spread of smoking was drawn. In Sweden the lung cancer mortality among women has increased during the last decade, while it has decreased among men, which likely mirrors changes in smoking patterns over the last 20 years. ${ }^{5}$ Based on the results of a recent analysis of between-country variations in mortality, it is proposed that both structural (eg, national economic, political policies, poverty) and behavioural factors (eg, smoking, alcohol consumption) contribute to socioeconomic differences in survival. ${ }^{27}$ In our study deprived patients were more often found to be current smokers and to have alcohol dependency. However, these factors were accounted for in the multivariable analysis of risks for all-cause mortality.

Supporting the notion that socioeconomic disparities might be related to differences in management and quality of care is our finding that patients with lower household disposable income were less likely to have undergone preoperative PET and were more often diagnosed with lung cancer of unknown histopathology. Furthermore, patients in the lower income quintiles were less likely to receive minimally invasive surgery. There are two previous Swedish studies that report of a lower diagnostic intensity in socioeconomically disadvantaged patients with lung cancer. ${ }^{9}{ }^{10}$ In the study by Willén et al patterns of lung cancer management and mortality were analysed in a nationwide cohort using educational level as proxy for socioeconomic status. In addition to socioeconomic disparities in diagnostic intensity they also found that the more deprived patients were less likely to be assessed by a multidisciplinary team and that patients with early stage disease had a higher all-cause and cause specific mortality compared with the more affluent patients. ${ }^{10}$ Preoperative assessment with PET and the use of minimally invasive surgery (VATS) as treatment for stage I lung cancer is in accord with international guidelines $^{28} 29$ and, hence, its use could be viewed as a measure of quality of care. VATS lobectomy for early stage lung cancer has been associated with lower complication rates, reduced postoperative pain, improved recovery, quality of life and long-term survival, compared with traditional open surgery (thoracotomy lobectomy). ${ }^{30-32}$ In accord with our findings, insurance status, income and educational level were all associated with the likelihood of receiving VATS in a study performed in the USA. ${ }^{33}$ The value of multidisciplinary team assessments and decision-making is well established in various medical disciplines ${ }^{34} 35$ and has a class I recommendation in guidelines for cardiac surgery. ${ }^{36}$ For patients with lung cancer it has been shown that multidisciplinary team assessments improve documentation of disease stage and performance status, variables that form the basis for guidelinebased treatment decisions, ${ }^{37}$ and alters the initial management plan for more than half of the patients. ${ }^{38}$ Furthermore, patients who are first seen at a specialist centre with access to thoracic surgery had a 51\% increase in the likelihood of receiving surgical treatment. ${ }^{39}$

A Danish nationwide study found that socioeconomically deprived patients had an increased risk of presenting with advanced-stage lung cancer. ${ }^{40}$ Furthermore, socioeconomically deprived patients had longer waiting times from referral to diagnosis than recommended. In another nationwide Danish study, socioeconomically deprived patients with early stage lung cancer were found to be less likely to receive first-line treatment and to have a greater risk of death. ${ }^{6}$ The adjusted HRs for death were highest in the first 6 months after diagnosis, and thus, according to the authors, supporting the hypothesis that socioeconomic disparities in stage at diagnosis and access to first-line treatment influences survival in lung cancer patients. In our study, that only included surgical patients, we found no relationship between household disposable income and cancer stage.

Sweden has several nationwide health-related registers managed by government authorities that are available for use in medical research. ${ }^{16-18}$ Some of these national registers have been described previously. ${ }^{41}$ Individual level cross-linking of information in the registers is facilitated by use of the personal identification number given to all persons residing in Sweden. ${ }^{15}$ The National Patient Register, managed by the Swedish National Board of Health and Welfare, has complete nationwide coverage of patient treatment facilities since 1987 and has been thoroughly validated. ${ }^{16}$ The LISA database has been described in detail by Ludvigsson et al and contains highly complete data on occupation, education and income. ${ }^{17}$

Multiple socioeconomic and sociocultural factors exist simultaneously and interact and thus have a combined and complex effect on health risks and disease outcomes. Nonetheless, it is important to attempt to better understand how socioeconomic inequalities affect survival in lung cancer patients considering the yet poor over-all survival. Taken together, the results of this study suggest that differences in survival after lung cancer surgery in Sweden might partly be attributed to socioeconomic disparities, despite tax-funded universal health coverage. The factors or underlying mechanisms that mediate the association between household disposable income and survival can only be speculated. However, it is reasonable to assume that at least some of the causative factors would be modifiable, and research efforts should be directed at identifying those.

The strengths of our study include the population-based design and the use of national high-quality registers which offer detailed prognostic information and complete and accurate follow-up. However, we did not have information on potential confounding factors such as diet, physical activity and social support, factors that have been associated with socioeconomic status and that could influence prognosis. Another limitation of the study was that we did not have information regarding cause of death. We acknowledge that the study design only allows speculation on what the underlying mechanisms of the findings could be and that future studies are needed to explore causality.

\section{CONCLUSION}

We found that income disparities were associated with survival inequalities in patients who underwent pulmonary resections for lung cancer in Sweden, in spite of a tax-funded universal healthcare system granting citizens equal access to care.

Acknowledgements The authors are grateful to the steering committee of ThoR for the contribution of data for this study.

Contributors VJ and US equally contributed to all aspects of this work. All authors contributed to the preparation and approved the final version of the manuscript.

Funding This work was supported by the Swedish Heart-Lung Foundation (grant numbers 20160522, 20160525 and 20180400 to US), Åke Wiberg Foundation (grant number M18-0016 to US), Karolinska Institutet Foundations and Funds (grant numbers 2018-01784 to US and 2018-01530 to VJ), the regional ALF agreement 
between Region Stockholm and Karolinska Institutet (grant number 20180114 to US).

\section{Competing interests None declared.}

Patient consent for publication Not required.

Ethics approval This study was granted ethical approval by the Swedish Ethical Review Authority and the need for informed consent was waived (registration number: 2017/1435-31).

Provenance and peer review Not commissioned; externally peer reviewed.

Data availability statement All data relevant to the study are included in the article or uploaded as supplementary information.

Open access This is an open access article distributed in accordance with the Creative Commons Attribution Non Commercial (CC BY-NC 4.0) license, which permits others to distribute, remix, adapt, build upon this work non-commercially, and license their derivative works on different terms, provided the original work is properly cited, appropriate credit is given, any changes made indicated, and the use is non-commercial. See: http://creativecommons.org/licenses/by-nc/4.0/.

\section{ORCID iDs}

Veronica Jackson http://orcid.org/0000-0002-1301-8440

Ulrik Sartipy http://orcid.org/0000-0003-2707-0263

\section{REFERENCES}

1 Forrest LF, Adams J, Wareham $\mathrm{H}$, et al. Socioeconomic inequalities in lung cancer treatment: systematic review and meta-analysis. PLoS Med 2013;10:e1001376.

2 Chetty R, Stepner M, Abraham S, et al. The association between income and life expectancy in the United States, 2001-2014. JAMA 2016;315:1750-66.

3 Kinge JM, Modalsli JH, Øverland S, et al. Association of household income with life expectancy and cause-specific mortality in Norway, 2005-2015. JAMA 2019;321:1916

4 Statistics Sweden. Demographic report 2016:2. life expectancy and mortality in different social groups. Available: https://www.scb.se/hitta-statistik/statistik-efteramne/befolkning/befolkningsframskrivningar/demografisk-analys/pong/publikationer/ livslangd-och-dodlighet-i-olika-sociala-grupper/ [Accessed 12 Nov 2019].

5 Public Health Agency of Sweden. Public health development - annual report 2019, 2019. Available: https://www.folkhalsomyndigheten.se/publicerat-material/ publikationsarkiv/f/folkhalsans-utveckling-arsrapport-2019/ [Accessed 12 Nov 2019].

6 Dalton SO, Steding-Jessen M, Jakobsen E, et al. Socioeconomic position and survival after lung cancer: influence of stage, treatment and comorbidity among Danish patients with lung cancer diagnosed in 2004-2010. Acta Oncol 2015;54:797-804.

7 Greenwald HP, Polissar NL, Borgatta EF, et al. Social factors, treatment, and survival in early-stage non-small cell lung cancer. Am J Public Health 1998;88:1681-4.

8 Johnson AM, Johnson A, Hines RB, et al. The effects of residential segregation and neighborhood characteristics on surgery and survival in patients with early-stage nonsmall cell lung cancer. Cancer Epidemiol Biomarkers Prev 2016;25:750-8.

9 Berglund A, Holmberg L, Tishelman C, et al. Social inequalities in non-small cell lung cancer management and survival: a population-based study in central Sweden. Thorax 2010;65:327-33.

10 Willén L, Berglund A, Bergström S, et al. Educational level and management and outcomes in non-small cell lung cancer. A nationwide population-based study. Lung Cancer 2019;131:40-6.

11 Dalén M, Ivert T, Holzmann MJ, et al. Household disposable income and long-term survival after cardiac surgery: a Swedish nationwide cohort study in 100,534 patients. J Am Coll Cardiol 2015;66:1888-97.

12 Benchimol El, Smeeth L, Guttmann A, et al. The reporting of studies conducted using observational Routinely-collected health data (record) statement. PLoS Med 2015; 12:e1001885

13 von Elm E, Altman DG, Egger M, et al. The strengthening the reporting of observational studies in epidemiology (STROBE) statement: guidelines for reporting observational studies. J Clin Epidemiol 2008;61:344-9.

14 The Swedish national quality register for general thoracic surgery (ThoR). Available: https://www.ucr.uu.se/thor/ [Accessed 12 Nov 2019].

15 Ludvigsson JF, Otterblad-Olausson P, Pettersson BU, et al. The Swedish personal identity number: possibilities and pitfalls in healthcare and medical research. Eur J Epidemiol 2009;24:659-67.

16 Ludvigsson JF, Andersson E, Ekbom A, et al. External review and validation of the Swedish national inpatient register. BMC Public Health 2011;11:450.
17 Ludvigsson JF, Svedberg P, Olén O, et al. The longitudinal integrated database for health insurance and labour market studies (LISA) and its use in medical research. Eur J Epidemiol 2019;34:423-37.

18 Ludvigsson JF, Almqvist C, Bonamy A-KE, et al. Registers of the Swedish total population and their use in medical research. Eur J Epidemiol 2016;31:125-36.

19 Oken MM, Creech RH, Tormey DC, et al. Toxicity and response criteria of the eastern cooperative Oncology Group. Am J Clin Oncol 1982;5:649-56.

20 White IR, Royston P, Wood AM. Multiple imputation using chained equations: issues and guidance for practice. Stat Med 2011;30:377-99.

21 White IR, Royston P. Imputing missing covariate values for the COX model. Stat Med 2009;28:1982-98.

22 Maruthappu M, Watkins J, Noor AM, et al. Economic downturns, universal health coverage, and cancer mortality in high-income and middle-income countries, 1990 2010: a longitudinal analysis. Lancet 2016;388:684-95.

23 Van der Heyden JHA, Schaap MM, Kunst AE, et al. Socioeconomic inequalities in lung cancer mortality in 16 European populations. Lung Cancer 2009;63:322-30.

24 Greenberg ER, Chute CG, Stukel T, et al. Social and economic factors in the choice of lung cancer treatment. A population-based study in two rural states. N Eng/ J Med 1988;318:612-7.

25 Yu XQ, O'Connell DL, Gibberd RW, et al. Assessing the impact of socio-economic status on cancer survival in New South Wales, Australia 1996-2001. Cancer Causes Control 2008;19:1383-90.

26 Mackenbach JP, Stirbu I, Roskam A-JR, et al. Socioeconomic inequalities in health in 22 European countries. N Engl J Med 2008:358:2468-81.

27 Mackenbach JP, Bopp M, Deboosere P, et al. Determinants of the magnitude of socioeconomic inequalities in mortality: a study of 17 European countries. Health Place 2017;47:44-53

28 Lim E, Baldwin D, Beckles $M$, et al. Guidelines on the radical management of patients with lung cancer. Thorax 2010;65 Suppl 3:iii1-27.

29 Postmus PE, Kerr KM, Oudkerk M, et al. Early and locally advanced non-small-cell lung cancer (NSCLC): ESMO clinical practice guidelines for diagnosis, treatment and followup. Annals of Oncology 2017;28:iv1-21.

30 Al-Ameri M, Bergman P, Franco-Cereceda A, et al. Video-Assisted thoracoscopic versus open thoracotomy lobectomy: a Swedish nationwide cohort study. J Thorac Dis 2018:10:3499-506.

31 Bendixen $M$, Jørgensen OD, Kronborg C, et al. Postoperative pain and quality of life after lobectomy via video-assisted thoracoscopic surgery or anterolateral thoracotomy for early stage lung cancer: a randomised controlled trial. Lancet Oncol 2016;17:836-44

32 Dziedzic R, Marjanski T, Binczyk F, et al. Favourable outcomes in patients with early-stage non-small-cell lung cancer operated on by video-assisted thoracoscopic surgery: a propensity score-matched analysis. Eur J Cardiothorac Surg 2018; 54:547-53.

33 Medbery RL, Gillespie TW, Liu Y, et al. Socioeconomic factors are associated with readmission after lobectomy for early stage lung cancer. Ann Thorac Surg 2016:102:1660-7.

34 Forrest LM, McMillan DC, McArdle CS, et al. An evaluation of the impact of a multidisciplinary team, in a single centre, on treatment and survival in patients with inoperable non-small-cell lung cancer. Br J Cancer 2005;93:977-8.

35 Kesson EM, Allardice GM, George WD, et al. Effects of multidisciplinary team working on breast cancer survival: retrospective, comparative, interventional cohort study of 13 722 women. BMJ 2012:344:e2718.

36 Nishimura RA, Otto CM, Bonow RO, et al. 2014 AHA/ACC guideline for the management of patients with valvular heart disease: a report of the American College of Cardiology/American heart association Task force on practice guidelines. J Thorac Cardiovasc Surg 2014;148:e1-132.

37 Boxer MM, Vinod SK, Shafiq J, et al. Do multidisciplinary team meetings make a difference in the management of lung cancer? Cancer 2011;117:5112-20.

38 Ung KA, Campbell BA, Duplan D, et al. Impact of the lung oncology multidisciplinary team meetings on the management of patients with cancer. Asia Pac J Clin Oncol 2016;12:e298-304.

39 Rich AL, Tata LJ, Free CM, et al. Inequalities in outcomes for non-small cell lung cancer: the influence of clinical characteristics and features of the local lung cancer service. Thorax 2011;66:1078-84.

40 Dalton SO, Frederiksen BL, Jacobsen E, et al. Socioeconomic position, stage of lung cancer and time between referral and diagnosis in Denmark, 2001-2008. Br J Cancer 2011;105:1042-8

41 Glaser N, Jackson V, Holzmann MJ, et al. Aortic valve replacement with mechanical vs. biological prostheses in patients aged 50-69 years. Eur Heart J 2016;37:2658-67. 